УДК 81.161 .1

Г. В. Токарев

\title{
КВАЗИЭТАЛОНЫ ЧЕРЕЗ ПРИЗМУ ГЕНДЕРА
}

\author{
Токарев Г. В. Квазіеталони крізь призму гендеру. \\ У статті в гендерному аспекті розглядаються номінації стандартів людини. \\ Ключові слова: мова, культура, стереотип, квазіеталон, гендер. \\ Токарев Г. В. Квазиэталоны через призму гендера. \\ В статье в гендерном аспекте рассматриваются номинации стандартов человека. \\ Ключевые слова: язык, культура, стереотип, квазиэталон, гендер. \\ Tokarev G. V. Quasistandards through the lens of gender. \\ The article considers the gender dimension of the category standards of man. \\ Key words: language, culture, stereotype, quasi standard, gender.
}

Квазиэталоны являются вербализаторами стереотипных представлений о человеке. Одним из наиболее значимых здесь оказывается гендерный признак. Большинство квазиэталонов гендерно симметрично. Это характеризует русскую лингвокультуру как гармоничную, имеющую развитые мужское и женское начала, значимыми для русской лингвокультуры становятся представители обоих полов. Гендерная симметрия выражается с помощью аффиксов, распространителей (лексически) или семантически: актёр / актриса, король / королева, мальчик на побегушках / девочка на побегушках.

Особенно интересны квазиэталоны, демонстрирующие асимметрию. Условно данные явления мы обозначим как maskulinum tantum и femininum tantum, то есть признаки характеризующие только мужчин и только женщин. Как известно, главным предметом лингвокультурологии является образ. Именно он выступает в роли ограничителя при формировании (ㄷ.‥ В. Токарев, 2011. 
противоположной гендерной семантики. Так, образные основания, указывающие на типичные мужские занятия, не допускают появления женской семы: сапожник, сеятель, солдат, семинарист. Отсутствует она, если образ указывает на типичные мужские физиологические признаки: борода, на названия, связанные с сложившимся социальным статусом: брат меньшой, вдова соломенная. Особенно продуктивна гендерная асимметрия продуктивна в рамках акционального кода. Номинации maskulinum tantum отражают черты патриархатного уклада жизни.

Среди асимметричных в гендерном отношении номинаций особую группу представляют стереотипы определённых типов сексуально детерминированного поведения: червонный валет, гусар, христова невеста и др. При этом номинации мужчин, как правило, имеют положительную семантику, женщин - отрицательную.

Квазиэталоны, связанные с антропоморфным культурным кодом, особенно с образными основаниями-соматизмами, демонстрируют гендерную симметрию. Её находим у квазиэталонов биоморфного культурного кода. Здесь учитывается половая принадлежность животного. Ср.: барбос, боров, бык, жеребеи. Образы представителей разных полов одного живого существа могут репрезентировать не коррелирующие друг с другом стереотипные представления. Ср.: ворон 'о человеке, приносящем беду, использующем чужое несчастье в своих целях' // ворона 'о нерасторопном, неловком человеке, простофиле'. В данном случае разные функциональные признаки птицы генерируют формирование коннотаций, которые становятся почвой для семантики квазиэталона. Поскольку гендерный аспект сознанием редуцируется, корреляция образа «мужское / женское» разрушается и одна и другая лексическая единица становится формой для вербализации представлений как о мужчине, так и о женщине. В рамках биоморфного кода номинации maskulinum tantum связаны с поведением животных и птиц, здесь преобладают отрицательные оценки, номинации femininum tantum связаны с внешним видом и поведением вспомогательного объекта обозначения. Доминирует положительная семантика. Ср.: баран, мышиный жеребчик, кабан, лев, крокодил, пёс, голубь сизокрыльй, гусь, индюк, петух // газель, лань, горлица, лебёдушка.

Заметны тенденции, которые мы называем феминизацией и маскулинизацией, при которых номинации, типичные для одного пола, используются для обозначения лиц другого пола. Так, становятся распространёнными словоупотребления типа: она мой оруженосец, палач, паж, адъютант, богатырь, солдат и др. Маскулинизация представлена менее продуктивно: балабол, проститутка, кобыла, красная девица, и др. Характерно, что при феминизации значение в большинстве случаев приобретает положительную сему, а при маскулинизации - всегда отрицательную. Этот факт отражает культурную установку о недопустимости для мужчины брать на себя женские практики, свойства и признаки. 
Квазиэталоны, связанные с анимическим (выделяется по базовому образу «природная стихия») и с биоморфным кодом (с базовым образом «насекомое»), демонстрируют гендерную симметрию, что может служить аргументом в пользу того, что незначительность вспомогательного объекта становится прецедентом для отсутствия гендерной дифференциации.

В ряде семантических групп дифференциация квазиэталонов на мужские и женские вообще отсутствует. К таким группам относятся «Характеристика человека по наличию материальных ценностей», «Характеристика человека по отношению к материальным ценностям», «Наименования лжецов», «Характеристика человека по параметру новизны», «Характеристика человека по отношению к свободе», «Наименование пьяного человека», «Наименования, указывающие на ценность человека». Это означает, что для языкового сознания безразлична дифференциация на мужское и женское в указанных смысловых аспектах.

Обратимся к квазиэталонам maskulinum tantum и femininum tantum разных семантических групп и попытаемся обозначить аспекты, которые отличают мужчин и женщин в русской языковой картине мира.

Для женщины весьма важным является соответствие стандарту внешнего вида. Значимыми становятся параметры веса, осанки, роста. Стандарт красоты фиксируют квазиэталоны: куколка, розан, фея, пава. Отклонения от стандарта отражают квазиэталоны: кубышка, кувалда, кобыла. При этом в мужском образе языковое сознание фокусирует своё внимание на параметре веса. В традиционной культуре избыток веса у мужчины оценивается отрицательно: боров, кабан, налим. Для территориальной субкультуры этот признак не является определяющим. Языковое сознание маркирует характеристику «опрятность / неряшливость»: опущенник 'о неряшливом мужчине'.

Разница наблюдается и в категоризации параметра возраста. Так, в мужской сфере фиксируется аспект юного возраста, в женской - наоборот, старого. Ср.: мальчик / христова невеста, старая скворечница. Данную оппозицию можно истолковать так: для мужчин - плох юный возраст, для женщин - преклонный. Эта оппозиция позволяет эксплицировать ценности русского сознания: для мужчины важен опыт, приобретаемый с возрастом, для женщины - внешние данные, которые с возрастом ухудшаются. Этот вывод подтверждают квазиэталоны семантической группы «Характеристика человека по имеющемуся у него опыту, знаниям». Ср.: о мужчинах. Старый волк / иуцик. Первый квазиэталон выражает положительную оценку, второй - отрицательную.

Значимым для мужчины становится параметр физической силы: бык, вол, лев, богатырь.

В аспекте свойственных человеку практик объективацию квазиэталонами находят единицы женской сферы. Так, важным для женщины является сноровка. Ср.: клуша 'о неповоротливой, неуклюжей 
женщине'. В территориальных субкультурах языковое сознание маркирует признак болтливости: каркуша, курва, острохвостка, перемьввайка, пищея, побрякушка. Не одобряется шумное, придирчивое, сварливое поведение женщины: квакушка, кудака, оскалённая, пила Характерно, что мужские признаки, которые могли бы проявиться в процессе выполняемой деятельности, не объективированы.

В характере мужчины подчёркивается смелость. Ср.: гусар, лев, сокол, орёл // девииа красная. В женской сфере это качество не фиксируется, однако эксплицируется антистандарт «злая женщина»: крысуха, чёртова перечница.

Существует мнение, что русское сознание отрицательно маркирует аморальное поведение женщины и толерантно к аналогичным поступкам мужчины. Квазиэталоны русского языка не поддерживают эту тенденцию. Данный ментальный аспект обладает относительно симметричной номинацией. Ср.: голубица, камелия, сука // мышииный жеребчик, рыщарь, кобель. Для мужчин становится значимым стандарт социальной оценки, его успешности, адекватности общественным нормам действий: джентельмен, рыщарь, гусар, медведь 'о малокультурном, грубом мужчине', лакей, пёс 'о мужчине, вызывающем негодование, заслуживающем презрения своим поведением, поступками’. Безусловно, что этот аспект представлен и номинациями женщин, но эти квазиэталоны единичны: светская львища.

Таким образом, в гендерном аспекте наиболее интересны квазиэталоны maskulinum tantum и femininum tantum. Они объективируют как стандарты, так и антистандарты человека. В мужчине русское языковое сознание выделяет параметр физической силы, опыта, смелости, социальной значимости. В женщине - внешней привлекательности, молчаливости, доброты, сноровки. Мужской портрет статичен, женский динамичен.

\section{Литература}

1. Алефиренко Н. Ф. Поэтическая энергия слова. Синергетика языка, сознания и культуры / Н. Ф. Алефиренко. - М. : Academia, 2002. - 392 с.

2. Алефиренко Н. Ф. Проблемы вербализации концепта / Н. Ф. Алефиренко. - Волгоград : Перемена, 2003. - 95 с.

3. Афанасьев А. Н. Мифы, поверья и суеверия славян : в 3-х т. / А. Н. Афанасьев. - М. : Эксмо, СПб : TERRA FANTASTIKA, 2002.

4. Балакай А. Г. Доброе слово. Словарь-справочник русского речевого этикета и простонародного доброжелательного обхождения : в 2-х т. / А. Г. Балакай. - Кемерово, 1999.

5. Даль В. И. Толковый словарь живого великорусского языка : в 4-х т. / В. И. Даль. - М. : Терра, 1995.

6. Красных В. В. Этнопсихолингвистика и лингвокультурология / В. В. Красных - М. : Гнозис, 2002. -283 c.

7. Лотман Ю. М. Семиосфера / Ю. М. Лотман. - СПб. : Искусство СПБ, 2000. - 704 с.

8. Потебня А. А. Мысль и язык / А. А. Потебня. - М. : Лабиринт, 1999. - 300 с.

9. Телия В. Н. Русская фразеология : семантико-прагматический и лингвокультурологический аспекты / В. Н. Телия. - М. : Шк. «Яз. рус. культуры», 1996. - 284 с. 